\title{
Modeling, Simulation and Stability Analysis using MATLAB of A D-STATCOM Based on Mitigation
}

\author{
Aaliya Ahmed, Parikshit Bajpai
}

\begin{abstract}
This paper explores the implementation of a D-STATCOM integrated model for voltage (V) stability of a hybrid power supply that is connected to a low-power distribution grid. We are currently not in a position to make effective use of clean energy sources (ES). Work is ongoing to enhance content consistency and interconnection facilities. In this paper, the integrated D-STATCOM model has been used to minimize hybrid device voltage instability. A framework in MATLAB and Simulink was designed and evaluated under different conditions by using the Simpower Systems toolbox.

Keywords: Multilevel Inverters hybrid topologies, THD, PWM, phase shift pulse width modulation, CHB, Renewable Energy, Boost converter, Solar System, sinusoidal pulse width modulation, Solar power, Solar panel, MPPT.
\end{abstract}

\section{INTRODUCTION}

The Renewable energy (RE) source is ES that is not lost if their energy (E) is used. Human utilization to RE includes technology that influences common wonders like daylight, waves, wind(W), water stream, a biological process like anaerobic digestion, geothermal warmth \& biological hydrogen generation. Sources of E referenced above, A great deal of progress has been made in innovation for wind energy (WE) harnessing. $\mathrm{W}$ is the movement of masses of air delivered by irregular warming of the world's surface by the sun. As a result, these varieties produce forces that move air masses around to adjust worldwide temperatures(T) or, on a lot littler scale, T between the land \& ocean or the hills. We are not just a steady source of E.[4 ] It always differs or gives E to unexpected blows [4].

WP generation has attracted unprecedented attention, with many wind power (WP) stations operating around the world. Enlistment devices will be used as generators(G) for WP stations, Nevertheless, improvement of latest permanent magnet (PM) G, Advancement of AC to DC to AC transition or this is advantages for the value of Output power makes different arrangements necessary [8]. The new approach is the use of PM synchronous variable speed generator \&

Revised Manuscript Received on April 25, 2020.

* Correspondence Author

Aaliya Ahmed*, Department of Electrical Power Engineering, Shri Ram Institute of Technology, Jabalpur, India. Email: ahmed.aaliya246@gmail.com

Parikshit Bajpai, Department of Electrical Power Engineering, Jabalpur Engineering College, Jabalpur, India. Email: bajpai.parikshit@gmail.com

(C) The Authors. Published by Blue Eyes Intelligence Engineering and Sciences Publication (BEIESP). This is an open access article under the CC BY-NC-ND license (http://creativecommons.org/licenses/by-nc-nd/4.0/) transformation structure, The STATCOM \& Static Synchronous Compensator is a control gadget used to replace power transmission networks (PTN). It is based around the power supply of the hardware voltage-source converter(C) that can be used as a source or as a sink for AC reactive electricity in the electricity grid. It could also provide dynamic AC power when paired with a power source. Usually, STATCOM is implemented to support the low-power \& often low-voltage electricity network [2]. There are several specific uses of STATCOM devices, Involve WE modification and symphonic separation. Furthermore, the most widely-recognized use is for stability. In this paper, a total W ranch with PWM-based STATCOM C is shown to fit the lattice linked synchronous $\mathrm{W}$ generator system [2]. This paper analyzes theoretical \& re-enactment studies of a dissected generation of Matlab wind turbines.

\section{PHOTOVOLTAIC SYSTEM}

PVS (photovoltaic system) transforms the sunlight directly into electricity. PV cell(C) was the essential device for PVS Cells could be divided into arrays and panels The current \& voltage available at PV terminals will directly provide little loads, like DC motors \& lighting systems. [6] PVC is mainly the semiconductor(S) diode, a $\mathrm{p}-\mathrm{n}$ connection of which is revealed of light. PVC contains many types of S utilizing various processes of processing.

The light effect on the cell produces a charge carrier that causes electrical current if the cells are shorted.

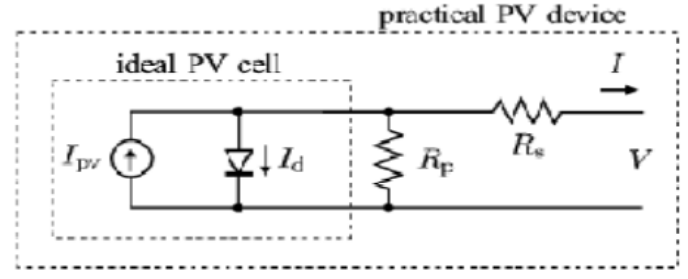

Fig. 1. Equivalent Circuit of a PV Device including series and parallel Resistances

In Fig, an equal PVC circuit is shown. 1. PVC on the diagram is expressed by the current source parallel to a diode. Rs \& Rp are parallel resistance \& series, respectively. A voltage and output current of PVC is defined by I \& V.

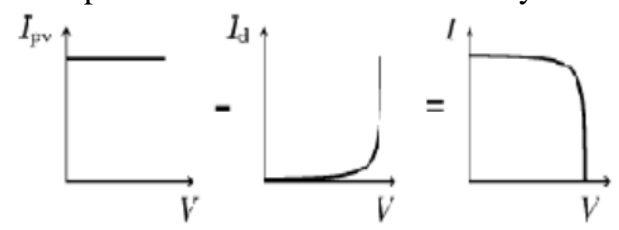

Fig. 2.V-I Characteristic of PV Cell 
Fig.2 shows the V-I characteristics of PVC [7]. Net cell current I consist of a diode current Id and light-generated Ipv:

$\mathrm{q}=$ Charge of electron

$\mathrm{k}=$ Constant Boltzmann

Io = Diode leakage current

$\mathrm{T}=$ Temperature of the junction of the $\mathrm{pn}$

$\mathrm{a}=$ Constant Diode Ideality.

The particular eq.(1) of PVC isn't an I-V element of practical PV array consisting of several connected PVC, and the study of the features of PV array terminals(T) requires the addition of specific parameters for the essential calculation. $\mathrm{I}=\mathrm{Ipv}-[\exp \mathrm{V}+\mathrm{RsIVta}-]-\mathrm{V}+\mathrm{RsI} / \mathrm{Rp}$

Thermal voltage (TV) of an Ns cell array is connected in sequence. The cells connected in series have a higher OV The I-V properties of functional PVC with (MPP) Maximum Power Point and short-circuit current (Isc) \& (Voc) open-circuit V can be seen in Fig.3 MPP was the point where maximum power is provided.

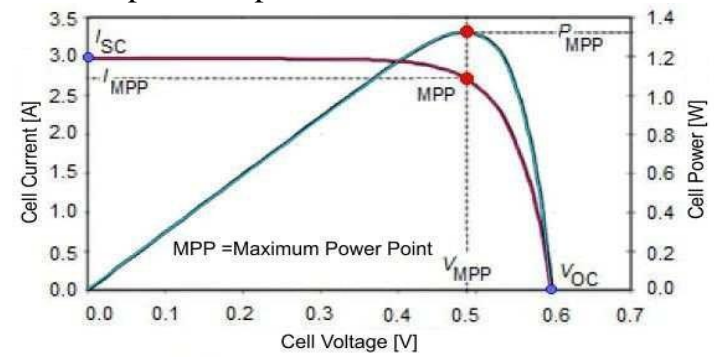

Fig. 3. I-V Characteristic of Practical PV Module.

Imp \& Vmp are both V \& present at MPP.Performance of PV cell isn't alike during a day; this is different from the changeable \& insulation temperatures (The radiations of amount). Furthermore, maximum insulation and temperature variations must be tracked to accomplish an Effective operation of PVS.

\section{STATCOM OVERVIEW}

STATCOM is shunt linked RP (reactive power) mitigation device able of absorbing \& generate RP where output could be improved to manage specific parameters of (EPS) electrical power system [2]. This is normally the solid-state switching $\mathrm{C}$ able of absorbing \& generate, real \& RP controllable independently Output terminals while being fed through energy storage (ESt) \& ES Device at its terminal input [6 ]. STATCOM is known to be a V-source converter which produces a 3-phase ac-output voltage (OV) series from a given DC (V) supply, every instep.

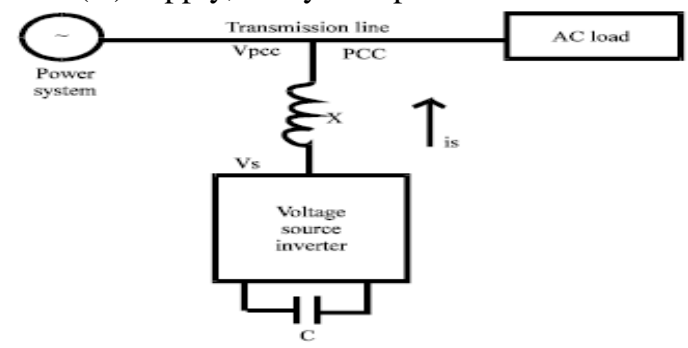

Fig. 4. Single Line STATCOM Power Circuit

Combined by related ac system $\mathrm{V}$ by relatively small reactions (Offered by the interface of the inductance of the reactor \& leakage of the coupling transformer). DC (V) is supplied by an ESt capacitor. VSC has the same quality current capability if operating with inductive-reactive current \& capacitive. VSC then gives STATCOM twice the dynamic range over a certain MVA rating of MVAR (still contributing to the design of compact)[6 ]. DC capacitor bank is used to stabilize the DC (V) controller required for VSC operation. STATCOM, RP is provided using V source C type power-electronic equipment. The amount of VSCs is coupled into a multi-pulse connection to form STATCOM[10]. In stable state \& VSCs operate with basic frequency shift to prevent a loss of C. But, Transient situations induced by a line fault, PWM mode (modulated pulse width) was used to prevent VSCs of entering fault V.STATCOM can withstand transients on the side of the ac if it is blocked. The STATCOM single-line power circuit in Fig.4, where VSC is connected by magnetic coupling to the utility bus

\section{D-STATCOM PRINCIPLE}

D-STATCOM is a controlled reactive source that involves $\mathrm{V}$ Source, C \& DC interface capacitor linked in shunt, generate \& capable of absorbing RP. The operating concepts of DSTATCOM focus on Accurate equivalence of the standard rotating synchronous compensator

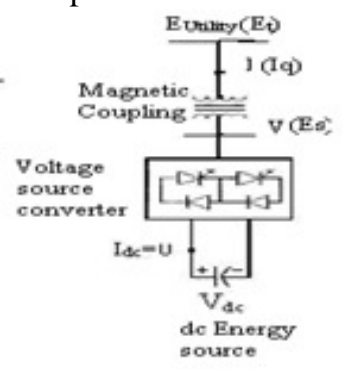

Fig. 5. Circuit Diagram of D-STATCOM.

VSC, AC (T) are linked to (PCC)common coupling point using an inductance that can be leakage inductance \& filter inductance of coupling transformer Fig 5. DC side of $\mathrm{C}$ is linked to DC source that carries a ripple current input for $\mathrm{C} \&$ main EST reactive component. If VSC, OV is equal to the AC (TV), no RP is provided to the device if an OV was greater than AC (TV), the DSTATCOM is a capacitive mode or vice versa \& operation. The quantity of RP flow is equivalent to the difference between the two $\mathrm{V}$ flows. For the use by the PCC of a DSTATCOM of a V Regulation, Compensation will be given the supply currents lead to $\mathrm{V}$ supply; In the case of (PFC) power factor correction, supply current must be in line with supply V. A methods of control mentioned in this paper were used to test the efficiency of D-STATCOM for harmonic mitigation \& PFC.

\section{HYBRID SYSTEM CONFIGURATION}

The integrated solution involves a wind energy conversion solution PV array and WECS, as well as power electronic converters. The single-line schematic of the system to be described. Eq. (1) models the perfect diode equation and a typical current source for PV array. [1].

Published By:

Blue Eyes Intelligence Engineering

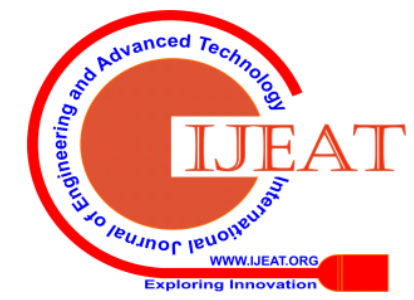


Where I0 \& Ipv is photovoltaic saturation currents and PV of an array \& $(\mathrm{Vt}=\mathrm{NskT} / \mathrm{q})$ is a TV of an array with Ns cells linked in sequence, When an array composed of parallel $\mathrm{Np}$ cell links, saturation currents \& PV may be represented as cell, Ipv $=\mathrm{Ipv}, \mathrm{Np}, \mathrm{I} 0=\mathrm{I} 0$, cellNp $\mathrm{W}$ energy has been tapped \& utilized to several activities by mankind since time immemorial. This paper uses a permanent magnet synchronous generator model with low maintenance costs. It can run at low speeds and no external enthusiasm of the other models is needed [3]. There is a basic model here. The model is dependent upon the turbine's steady-state power characteristics.

\section{SIMULATION MODELLING}

The modeled PV system consists of the components of the array of PV, the (VSC) voltage source converter, LCL filter, dc-dc BC(boost converter) \& power distribution system configuration. Element level models for a PV system, including the MPPT algorithm, are described in this section.

\section{A. PV Array \& MPPT Algorithm}

A model for single diode PVA is taken as of [10]. A characteristic V-I curve of PVA are for different levels of solar irradiance, whereas the ambient temperature is at $25 \mathrm{C}$. $\mathrm{V}$ at Vmpp, Maximum Power Point at every level of irradiance is shown in Fig. 4. The MPP which could be derived from PVA at the given time depends on the solar irradiance (SI) \& ambient temperature (AT). As SI \& AT are constantly varying, MPPT algo is required to track an MPP. Among an obtainable MPPT Something, The renewable Perturb \& Observe (P\&O), Incremental \& technique Conductivity (In C) Technique is two excellently-known MPPT. $\mathrm{P}$ and $\mathrm{O}$ technique was described as a simple MPPT algo.

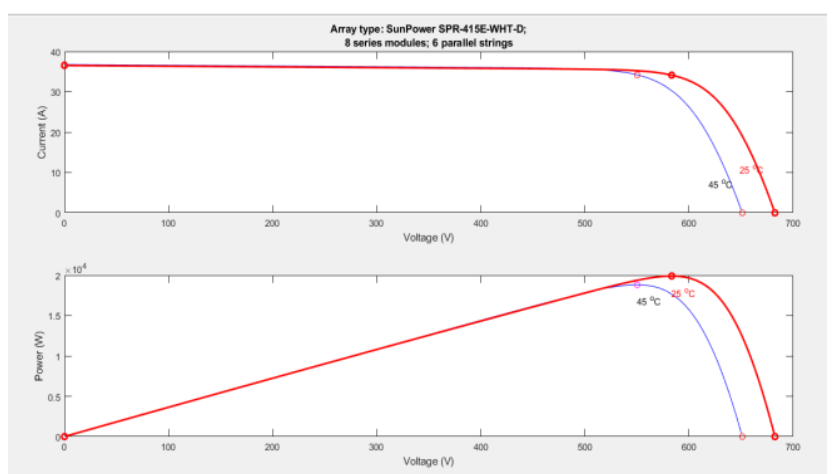

Fig. 6.characteristics of the PV module

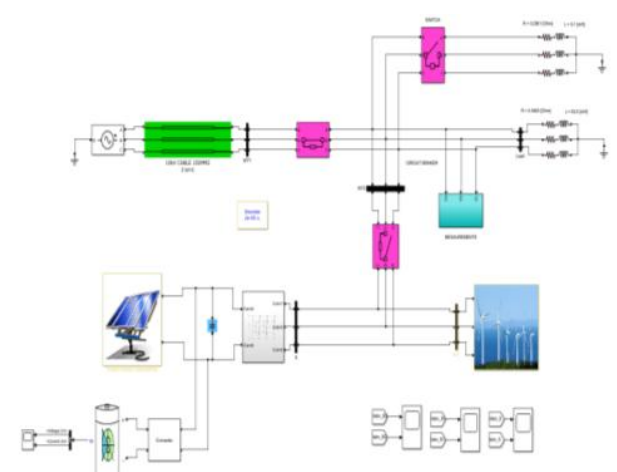

Fig. 7.Hybrid Power System

\section{B. Voltage Source Converter}

VSC of Fig. 6 is the full-bridge $C$ produced to bipolar transistor gate insulated switch. The VSC is capable of operating across all 4 quadrants. The A-rated effective power capability of the VSC. After injection of a sure amount of active power(AP) spare capacity of a VSC is used to inject \& absorb RP. VSC switching frequency, FSW, is $3 \mathrm{kHz} \&$ Unipolar sinusoidal pulse width system used.

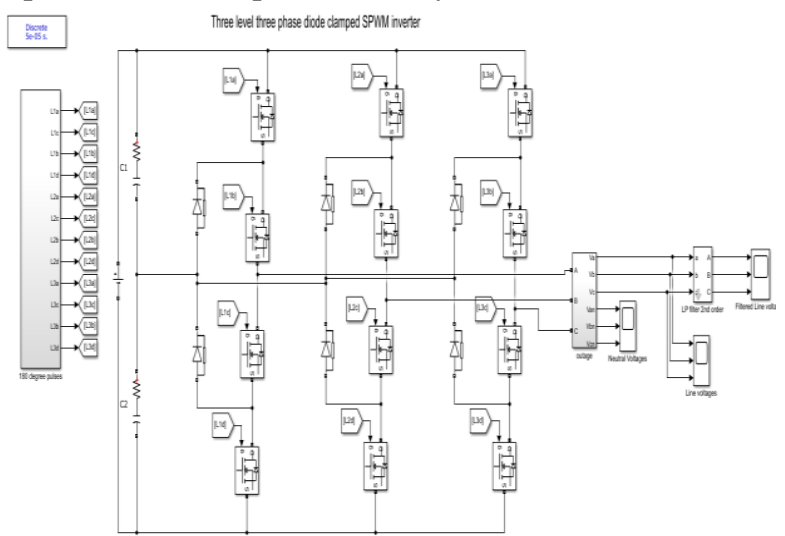

Fig. 8.is a full-bridge converter

\section{Selection of Dc-link Capacitor}

The Vdc dc-link(DCL) forms of the Vdc avg dc component, and the $100 \mathrm{~Hz}$ ripple $\mathrm{V}$. The expression of a peak-peak 100 $\mathrm{Hz} \mathrm{V}$ ripple, $\Delta \mathrm{Vdc}$, of DCL could be resulting as [16]. In (1) $\mathrm{Pg}$, The AP injected into the Cdc grid is basic angular frequency \& DCL capacitor of V grid avg. VDC avg is a 400 V model PV system.

The Cdc modeled PV system is measured as $12000 \mu \mathrm{F}$ to limit the Vdc value to approx 5 percent of Vdc average if the VSC injects $5.4 \mathrm{~kW}$ to AP into the distribution grid.

\section{Dc-dc Boost Converter}

The estimated power of dc-dc BC is Fig. 6 FDC, the switching frequency of $5 \mathrm{kHz}$. Inductor Ldc could be determined as defined in (2) to restrict present ripple \& $\Delta \mathrm{I}$, of current flow of inductor[13 ]. Vpv was V around a PVA in (2).

$\mathrm{Ldc}=\mathrm{Vpv}(\mathrm{Vdc}$ avg $-\mathrm{Vpv}) / \Delta \mathrm{IfdcVdc}$ avg (2)

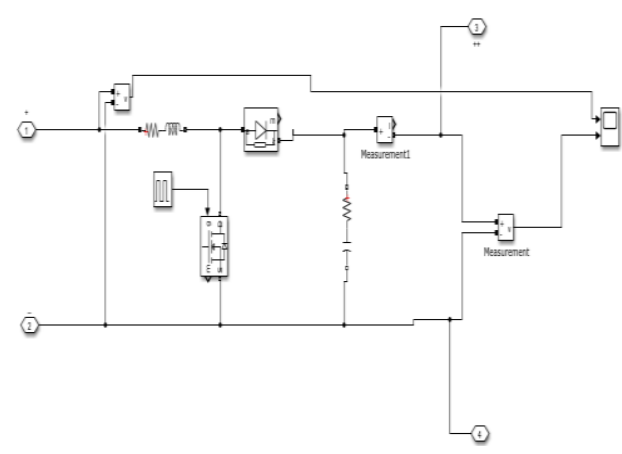

Fig. 9.DC to Dc Boost Converter

If $\mathrm{PV}$ array(A) is operated similarly to MPP, $\mathrm{Vpv}$ is closed $300 \mathrm{~V}$ according to like shown in Fig.4. As a result, an Ldc $=$ $9 \mathrm{mH}$ inductor could be computed to limit the value of I to 5\% 
whenever dc to dc BC operates at RC. The dc-dc BC decouples an ac-side dynamics of PVA[16 ]. Therefore, modeling the GC to a PV system, the PVA output Cpv capacitor is selected to 2.5 times the Cdc capacitor. With the chosen value in C PV \& $100 \mathrm{~Hz}, \mathrm{~V}$ ripple occurs everywhere.

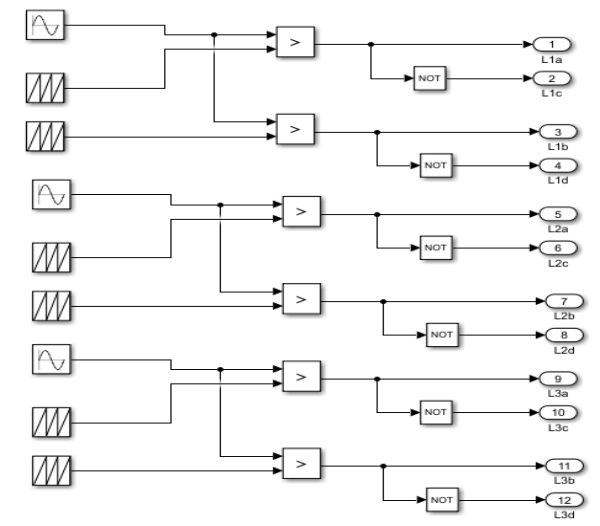

Fig. 10. PWM technique Used for Inverter

PVA is decreased to $10 \%$ of the $100 \mathrm{~Hz}$ dc-link V while VSC is operated at RC(rated capacity). The high time constant of Cpv Decouples, AC side and DC side of GC (grid-connected) PVS in general. Capacitor Cpv still minimizes the ripple current switch generated by the PVA.

\section{RESULT \& ANALYSIS}

A simulation (S) design of GC 3 phase PV system was established in Matlab S program S learn was conduct to assess the efficacy of PV system controllers and models In all S cases, the surface temperature of a PVA is assumed fixed at $25 \mathrm{C}$. The VSC was operated at RC with or without low HC order.

THD (Total harmonic distortion) to $\mathrm{S}$ grid $\mathrm{V}$ is not perfect. A magnitude of a low order current harmonics introduced into Power distribution of the grid (PDG) like a gain of basic current is Fig.9. Shows a reaction of the closed-loop current control (CLCC) \& DCL V (from 1000 to $200 \mathrm{~W} / \mathrm{m} 2$ at $\mathrm{t}=0.4$ s) controller to phase changes in solar irradiance. The new current reference is generated in the built-in PV system while the operating state is updated. As CLCC controls the current link closely, the steady-state error is almost 0 . It shows the ability of the latest controller meant to control the active \& RP injected independently.

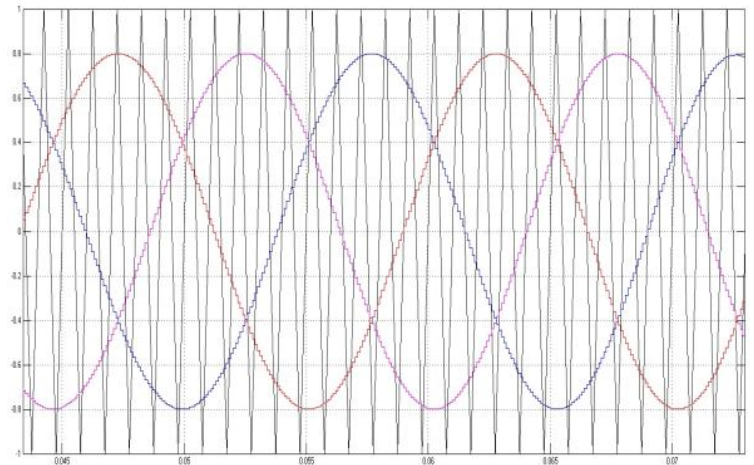

Fig. 11. Comparative Wave for Used for PWM

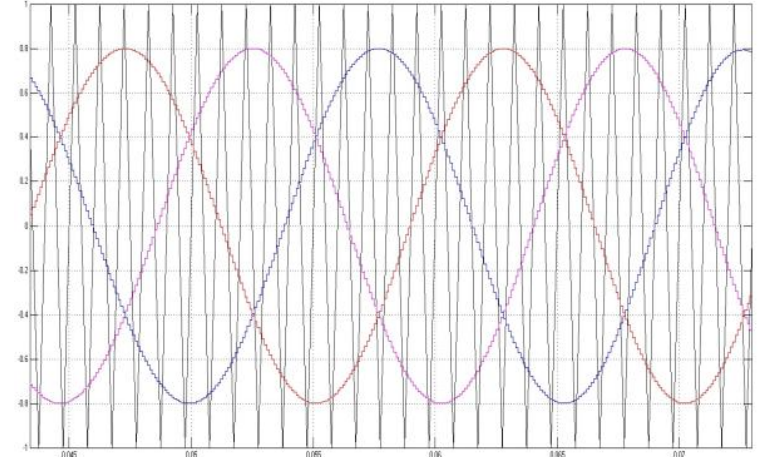

Fig. 12. Comparative Wave for Used for PWM

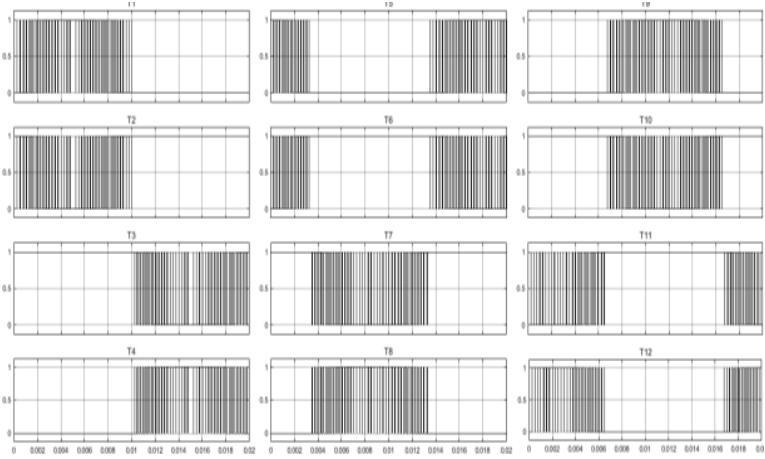

Fig. 13. Gate firing Pulses for Three Phase Inverter.

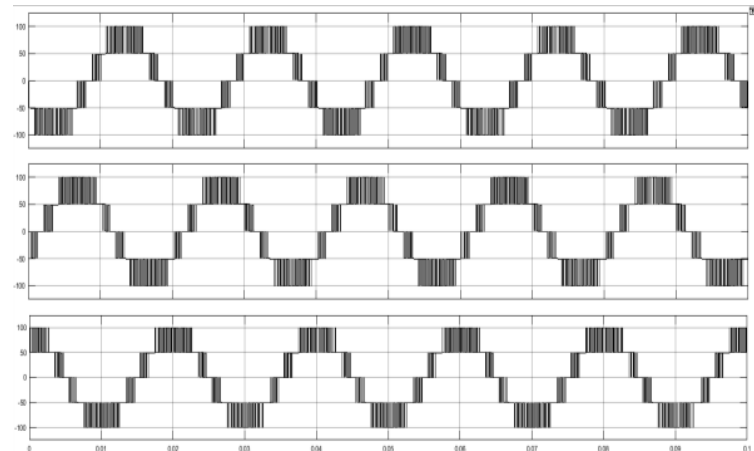

Fig. 14. The output waveform of Three Phase Inverter.

The performance of an MPPT algo, the dc-dc BC controller \& VSC power factor controller is shown in the variation of a solar irradiance illustration. PVA V was controlled by Vref's dc-dc BC controller Vpv by adjusting the dc-dc BC service cycle. MPP tracking direction of experimental changes in solar radiation. But once the solar irradiance has normalized, A common MPP was correctly calculated by an MPPT algo Figures may only appear in color for certain journals. Please verify with IJSTR that the journal you are submitting to does indeed accept color.

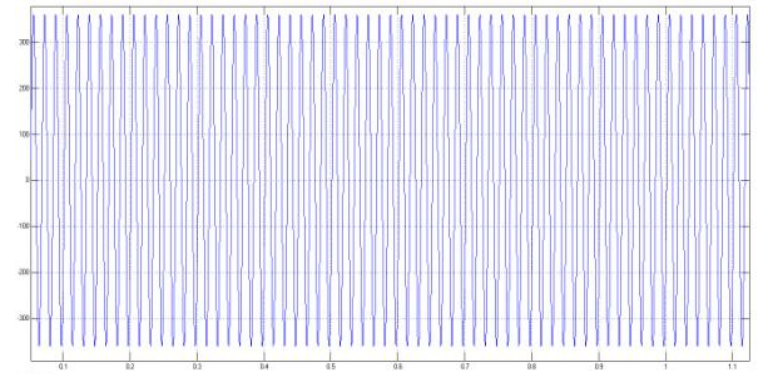

Fig. 15. The output voltage of the grid.

Published By:

Blue Eyes Intelligence Engineering

\& Sciences Publication

(C) Copyright: All rights reserved. 


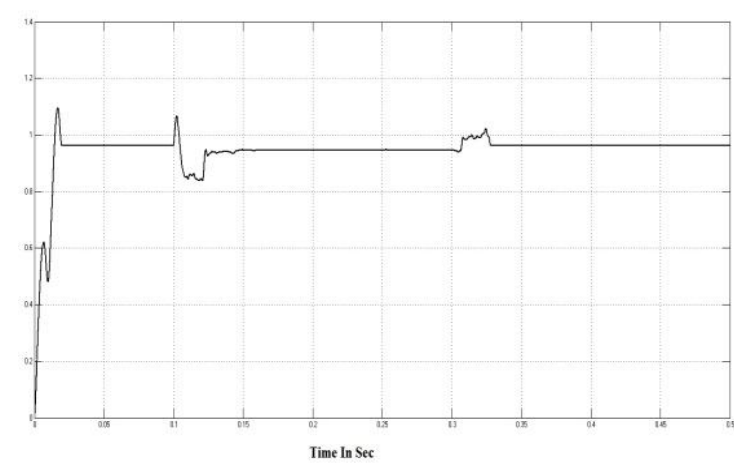

Fig. 16. Load Analysis.

\section{CONCLUSION}

To carry out an inquiry into the enhancement of power quality detailed information on the nature of power quality issues related to a specific location of complete understanding \& transmission lines of FACTS controllers \& devices. In this research, D-STATCOM is proposed to reduce a harmonics problem through industrial distribution systems in a fast \& cost-effective manner. Hysteresis failure current control (HFCC) algo uses the error signal, Ex. It's the difference among actual measured load $\mathrm{V}$ \& reference voltage, To make an inverter switch to use the (PWM) Pulse Width Modulation process. D-STATCOM controls the appropriate V component without any injection \& difficulty to quickly correct any enhancement in the V supply by keeping the V load constant \& balanced at par value. In this research, DSTATCOM showed the ability to decrease the harmonics issue and the overall harmonic decrease thru S execution. D-STATCOM output. Analysis of experimental \& S testing has shown that the suggested scheme is better. PQ Concept Control with HFCC algo focused on D-STATCOM can achieve better compensation features. Use this compensation form, (Total Harmonics Distortion) THD decreased to 2.21 percent.

\section{REFERENCES}

1. Otadui, UnaiViscarret, Izaskun Zamakona, "Improved STATCOM Operation Under Transient Disturbances for Wind Power Applications", 2007.

2. M. Chegaar, A. Lamri, and A. Chibani, "Estimating Global Solar Radiation Using Sunshine Hours", Physique Energétique (1998) 7 11.

3. Zaharim Azami, Razali Ahmad Mahir, Gim Tee Pei, Sopian Kamaruzzaman, "Time Series Analysis of Solar Radiation Data in the Tropics", European Journal of Scientific Research, Vol.25 No.4 (2009), pp.672-678.

4. Duffie John A, William Beckman A, "Solar Engineering of Thermal Processes, 3rd Edition, 2006, John Wiley and Sons Inc, pages 3 - 138.

5. Sen, Zekai, Solar energy fundamentals, and modeling techniques: atmosphere, environment, climate change, and renewable energy, Springer, 2008, pp 44-70.

6. Solar Radiation Hand Book, Solar Energy Centre, MNRE and Indian Metrological Department, 2008.

7. IMD Pune website, http://www.imdpune.gov.in/, accessed on 20th June 2010.

8. Hall James and Hall Jeffrey, "Evaluating the Accuracy of Solar Radiation Data Sources", Solar Data Warehouse, February 2010.

9. Saren Johnston, "Sunproofing Solar Cells Computer simulations help explain why solar cells degrade in sunlight", Insider, April 2003.

10. M. Chegaar, P. Mialhe, "Effect of atmospheric parameters on the silicon solar cells performance", Journal of Electron Devices, Vol. 6, 2008, pp 173-176.

11. Wohlgemuth John H, "Long Term Photovoltaic Module Reliability", NCPV and Solar Program Review Meeting 2003.
12. C.R. Osterwald, A. Anderberg, S. Rummel, and L. Ottoson, "Degradation Analysis of Weathered Crystalline-Silicon PV Modules", 29th IEEE PV Specialists Conference, New Orleans, Louisiana, May 20-24, 2002.

13. A.M. Reis, N.T. Coleman, M.W. Marshall, P.A. Lehman, and C.E Chamberlin, "Comparison OF PV Module Performance before and after 11 years of field exposure", Proceedings of the 29th IEEE Photovoltaics Specialists Conference New Orleans, Louisiana May 2002.

14. Fraunhofer Institute: Module Power Evaluation Report, commissioned by Schott Solar AG.

15. Ewan D. Dunlop, David Halton, "The Performance of Crystalline Silicon Photovoltaic Solar Modules after 22 Years of Continuous Outdoor Exposure", Prog. Photovolt: Res. Appl. 2006; 14:53-64.

16. Peter Klemchuk, Myer Ezrin, Gary Lavigne, William Halley, James Susan Agro, "Investigation of the degradation and stabilization of EVA-based encapsulant in field aged solar energy modules." Polymer Degradation and Stability 55 (1997) pp. 347-365.

17. Ian Muirhead and Barry Hawkins, "Research into new technology photovoltaic modules at Telstra Research Laboratories - What we have learned", 1996.

18. C.R. Osterwald, J. Adelstein, J.A. del Cueto, B. Kroposki, D. Trudell, and T. Moriarty, National Renewable Energy Laboratory (NREL), "Comparison of degradation rates of individual modules held at maximum power", 2006

19. Power Electronics Handbook Devices, Circuits, And Applications (Muhammad H. Rashid).

\section{AUTHORS PROFILE}

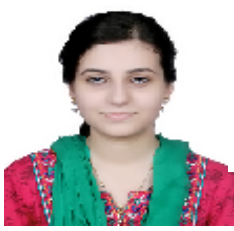

Aaliya Ahmed received a Master degree in Electrical Power Engineering from Shri Ram Institute of Technology, Jabalpur, M.P. Her research interests are in the field of Power system.

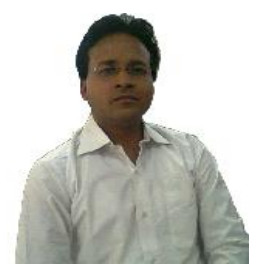

Parikshit Bajpai received Bachelor of Engineering (B.E). His research interests are in the field of Information Security Domain and also experienced in Project Management and delivery. He has 15 years of extensive experience in the Information Security domain. He has headed teams that provide information security services to multinational organizations. 